\title{
A Theoretical Postscript: Time, Space, the Self and the You, and Digital Media as Narrative Constructions
}

While elaborating the typology of narrations presented in the previous chapter, my research interest was focused on the narrative webs at the heart of the episodes, reflections, contextualizations, and aspirations reported on in the interviews, on the narrations behind the narrations, as it were. Elements of these "contextualized" narrations may be recounted explicitly or implicitly, and sometimes they are nothing more than a hunch. Meaning is only accorded to these narrations, however, when explicit and implicit elements are collated. In the process, the interdependencies between the pieces of the narrative jigsaw puzzle become visible, affording a vision of a meaning which extends beyond that of the individual pieces. As Jürgen Straub emphasizes, the implicit elements of a narration are just as present from a mental perspective as the explicit ones $(2013$, p. 78 ). They are part of the "experiential story of a subject talking about the self" $(2013, \text { p. } 78)^{1}$ in a similar fashion to the unconscious, which is not, however, the subject of this analysis.

The identified narrations which integrate the explicit and implicit elements as well as different phases and spheres of life remind us of what Vera Nünning has called "master narratives" (2013, p. 163), by which she understands the large-scale meaningful narrations which can be sorted into individual episodes $(2013$, p. 163). Thus, the overarching narration must not be seen as something static. Rather, it is much more likely that it is open to change, that it will be told in different manners at different

\footnotetext{
${ }^{1}$ All quotations from German publications were translated into English for this book.
}

(C) The Author(s) 2020 
points in time, that new episodes will be added and others omitted. It can also be the case that a second major narration emerges; this could exist side by side with the first or could even supplant it. Whatever the overarching narrations turn out to be, they are also always products of the circumstances in which they are recounted. These circumstances include both the historical point in time, along with its sociocultural implications, and, in the case of the study at hand, the context of the research, the specific research interests, and the cultural roots of the female researchers, which must have had an effect on what was said and how when talking to the Arab and American network actors. Such constraints are a general issue in research as every utterance is constituted depending on space and time. Nonetheless, subjectivity includes certain consistent facets which make up the irreducibility of the human subject discussed in Sect. 2.3. When Arif Dirlik claims, in connection with social transformation, that what is to come always bears the mark of what was before $(2010$, p. 36$)$, this applies equally to the level of the subject. In this respect, the assumption is that the narrations concerned and the images, strategies, experiences, and attitudes towards life expressed in them are not due to chance but boast elements of continuity.

The narrators are divided up over two instances, being both the narrators of and protagonists in their narrations (Ries, 2013, p. 41), and as such, they often live through what they tell for a second time on an emotional level. Constantly changing between these two roles when narrating also implies a shift between distance from and proximity to what is being narrated. This has consequences for the narrative processing of what has been experienced as well as for the construction of the Self. I will return to this point in Sect. 5.3.2.

This chapter pursues the question as to how the concepts presented in the second and third chapters, namely time and space, the Self and the You, and the structural characteristics of digital media, appear in the narrations under investigation and in what way these concepts and structural characteristics are manifested in these stories. This has already been touched on descriptively in connection with individual narrations; now a cross-comparison should help reveal overlapping tendencies across the individual narrations. The theoretical concepts of time, space, the Self, the You, and digital media can be identified in the different types of narrations but take on different forms in each type. This chapter builds on the previous one, addressing the theoretical interfaces. Familiarity with the previous chapter facilitates comprehension of the theoretical elaborations in the current one. 


\subsection{Time STAMPS}

Time appears in various types of narrations as biographical and sociocultural time.

\subsection{1 "I wanted to play football with the boys but ...": Biographical Time}

The most impressive time stamps in the narrations are the autobiographical traces which reference past or current life circumstances, which were formulated as a reason for something happening or not, or which were told to the researcher all the same, or at least could not remain hidden from her. Life stories are not static and invariable. They constitute themselves and change through narrating (Straub, 2013, p. 86). Subjects are involved in the genesis of their life stories in as much as they articulate what they have experienced as in a story (Straub, 2013, p. 96). When Norbert Meuter characterizes the doings in our life-world as a process of which narrating is a constitutive part $(1995, \mathrm{p} .164)$, on the one hand he characterizes narrating as doing and on the other hand he emphasizes the processual nature of life stories, as narrating is the doing through which life stories arise. They appear as a narrative framework encompassing the existence of an individual which integrates the various episodes brought forth by narrating (Straub, 2013, p. 111).

\subsubsection{The Present as a Consequence of the Autobiographical Past}

"The past as such does not exist," suggests Aleida Assmann. "It can only be made present by selecting, shaping and interpreting" (2012, p. 122). In the narrations related for the study at hand, the past was invoked both consciously and unconsciously. It was described as a cause for something happening, or was recognizable as such, or as a supporting factor.

A conscious invocation of an autobiographical past can be found in the stories about setting out and breaking away told by the 24-year-old American network actor who set out for Europe, the 24-year-old network actor from Bahrain who founded the network Mideast Youth (n.d.), and the 26-year-old Yemini blogger and journalist, as well as in the self-staging narration by the 23-year-old fashion blogger from Austria. The American recognizes that there is an important link between the stubbornness she developed as a child (one manifestation of which was refusing to play outside because she was not allowed to play football with the boys) and her 
setting out for another continent as a young woman. The 24-year-old Arab network actor identifies the determination to change her own life and that of others which she already felt as a "very young girl" as being the reason for her political commitment later on which was interpreted as an act of breaking away. The 23-year-old Austrian blogger tells a self-staging narration, but he, too, is aware of what motivated his self-staging activities. He mentions three causes which stem from the past: the importance of putting across "a good social image as a family" to the outside world; the fashion magazine Vogue, which awakened his passion for fashion as a means of self-representation when he was nine years old; and his grandmother, who "always took very meticulous care about the way she presented herself, but also to create a good impression in society."

The reasons that the 26-year-old Yemeni blogger gives as being responsible for her current actions and which are also part of a story about breaking away do not go so far back into the past. She considers her training as a journalist to be pivotal for being able to see through political relationships. This assumption illustrates Tilmann Habermas' proposition that life stories are not engraved in stone in childhood but that they can set a new course in adolescence and beyond as well (2011, p. 649).

How much truth is there in the stories from the past called up by the narrators? The cause-effect relations they present which appear to result in a logical picture are regarded as constructions in literature on the topic. Assmann observes that the past is "mould[ed] ... in order to lend support to an argument or an attitude" in the present (2012, p. 122). Jürgen Straub argues along similar lines when he assumes that the past can be changed retrospectively "in the light of a changed present and in anticipation of a new future" $(2013$, p. 111$)$. This is indicative that a narrated past fulfils a specific function for narrators, allowing them to see their own actions in the present as being logical and meaningful. In this respect, it is not important for the subject whether something really happened in the way it is described as happening (Ries, 2013, p. 36). What is important is that the narrated past gives the subject security on the basis of which perspectives for the future can develop. This is precisely what is interesting in this book, focusing as it does on an investigation of subjects' perspectives.

The past can also play a role in the genesis of life stories when subjects are not aware of it or, at best, only sense it. Examples of this can be identified in the self-staging narration of the 21 -year-old blogger from Italy who chose the nickname Gaia and in the seller narration related by the 
22-year-old blogger from Germany who promoted participatory projects. Both of them talk about events or experiences which they considered to have left a mark on their lives without establishing a connection between these and the focus of their narrations. Although the 21-year-old explained that Gaia, the heroine in the series of novels Fearless which she read when she was 12 , had inspired her to be more courageous, she did not say that Gaia-and this is my interpretation-had become a counter-model which helped her to cope with current turning points in her life, caused by starting university in a new town, even if she suspected that that was the case. The 22-year-old German blogger talked about the death of her brother, which happened when she was six, as a traumatic and defining event. She does not talk about how this early experience of loss could have left a mark on her life. I believe that there could be a connection with the participatory projects she launched in virtual space, which I see as attempts to create new social bonds and connectivity which could form the antithesis to her experience of loss through death. Possibly it is one attempt in a series of further attempts to bind other people to her.

A 24-year-old blogger who had emigrated from Ukraine to Germany when she was 10 or 11 repeatedly talked about her experiences of being ostracized in her new home which gave her the feeling of being nothing and not being able to do anything. Then again, she talked about her sparkly online presence, oriented towards the manga character Asuka, to which she dedicated a great deal of time and care. She also mentioned that she had become something of a celebrity in the manga scene. Here, too, I presume that her past experiences of discrimination have some bearing on her internet presence in the sense of the one being compensated for by the other.

The autobiographical past can take effect-whether consciously or unconsciously - as an incentive or an encouragement, as a dark spot or as a bad memory, thus helping to define the focus around which the orientations, feelings, and actions are grouped which result in a specific narration. It can also only take effect as a contributing factor, for example when present-day network actors already had access to digital technology in puberty and could thus acquire technical competences in the use of such media at an early age, when their parents have different cultural backgrounds, or when they were confronted with different cultures as a result of spending time in various countries as adolescents or could attend schools where English was taught. Such life circumstances and associated experiences can encourage interest in the Foreign, coming to terms with 
one's own culture, and exchange with network actors from other cultural spaces, supporting narrations in which interconnectedness, the management of boundaries, or setting out and breaking away occupy centre stage.

\subsubsection{Current Life Circumstances as Justifying or Supporting Factors}

As already suggested, it is not only a narrator's autobiographical past which can evoke certain narratives; the causative or supporting factors can also be found in current life circumstances. In the narratives under investigation, there are also current autobiographical upsets and upheavals, triggered by individuals or their families, or brought about by their belonging to a specific age group. In both cases, there are links to the stories which are told. The life of the 21-year-old American student who related an interconnectedness narration in which the sharing of experiences dominated must have been thrown into a disorderly state when his parents divorced and family members were strewn in all directions over the North American continent, and he, in addition, had to leave his home town and circle of friends behind when he started studying at a university in another state. His narration concentrates on activities which support interconnectedness in the form of sharing images and communications between the members of his family und making sure that he keeps in contact with his network of friends. The internet is an ideal medium for sharing, so he stays online all day. Another type of autobiographical upset was experienced by the 14-year-old German blogger who told a story about suppliers and sellers, presenting himself in his narration as a tester of purchasable products. At the time of the interview he had been recently diagnosed with a chronic illness which, time and again, made it impossible for him to have a social life. When he reviews technical appliances on his blog, presents recipes and his cooking experiences as well as photos to go with that, critiques documentaries, and uploads trailers, he creates an autonomous world for himself in which he can show off his competences and to which he always has access, unconstrained by his illness. The digitally assisted world of products which the 14-year-old creates with his blog is not a closed world reserved for him alone; rather it is one which is aimed at Others. In order to arouse Others' interests, he endeavours to meet their needs, to flesh out his articles carefully, and, to complement his product reviews, to tell others about his life, including his illness.

It is not events which go back a long way but current experiences which create the time stamps in the narrations of the two network actors. They appear as active participants in their own narrations (Müller-Funk, 2002, 
p. 172) whose actions are intended to mitigate or compensate for autobiographical upsets, or, as in the case of the 14-year-old, to draw new outlooks on life from these upsets by developing expertise.

In the transformation narrations of the 11- and 13-year-olds who live in different parts of Germany (cf. Sect. 4.5.1), there is another type of time stamp which has to do with belonging to a specific age group. These network actors are either at the onset of puberty or right in the middle of it. In puberty, which leads to adolescence, everything gets mixed up (Erdheim, 1988, p. 193). The transition has to be managed from childhood to the adult world. A horizon opens up with a wealth of options in the context of which decisions have to be made (Helsper, 1997, p. 177). In Claude Lévi-Strauss' “'hot' societies” (1962/1966, pp. 233ff.), such as in Western cultures, young people are expected to question traditions, to develop innovative creativity, and to restructure their personality, which is no longer attached to a family framework (Assmann, 2012, pp. 118-119; Erdheim, 1984, p. 296). Nonetheless, even in hot cultures, there are social rituals which demand a commitment to prevalent values, or should at least restrict deviations from those values, such as grades at school, parental prohibitions, and selection procedures at university and on the labour market. It is a phase of life marked by contradictions, which unleashes insecurity and, at the same time, challenges individuals to build on agency and future perspectives.

Such challenges are definitely present in the transformation narrations. The two 11- and 13-year-old male network actors describe clear goals which will determine their individual journeys into adulthood. The 13 -year-old is attempting to surround himself by things from the reservoir of transport and media technology, which he presents as proof of becoming an adult in his transformation narration; on top of that, he mentions his increased access to home pages which had previously been forbidden, which once again should provide proof of his responsible dealings with media technology. The 11 -year-old is reaching for the stars; he wants to become a famous football player, training both offline and online to achieve this goal, and he dreams of expensive fashion brands, getting closer to them at least with his nickname "Hardyboy." Both narratives tell of fantasies of omnipotence, which are typical of adolescents. According to Mario Erdheim, they draw their strengths from these fantasies, but they can also prove to be their weak spots (1988, p. 200).

The narration of the 12-year-old network actor which I entitled "the role player" (Sect. 4.5.2) is also indicative of struggles with the demand 
for agency. In the first place, this is illustrated by her participation in roleplaying games online and offline. She makes extensive use of the possibility to swap roles in the online role-playing games in particular, playing seven different roles in seven role-playing games, which indicates very intensive experimentation with different ways of acting and self-representations. A second indication for her involvement with demands to develop courses of action is a question which runs through her narrative like a golden thread, namely the question as to what is right and important, or unimportant, in life. She makes use of the virtual world of the internet to help her process this question.

Just like with the autobiographical past, upsets and upheavals in the present can influence the focus around which an individual narration develops. This serves to process experiences through narrative and to develop solutions (Augustin, 2015, p. 180), a function which the narrators do not have to be aware of in order to fulfil a function.

\subsection{2 “It's like a political awakening ...": Sociocultural Time}

Whereas in the transformation narrations, biographical life phases should be overcome, other narrations herald the overcoming of sociocultural epochs, namely those narrations about setting out and breaking away, interconnectedness, and managing boundaries which convey a message about a sociocultural epoch, at least when the narrations stem from Arab network actors and bloggers. They were telling their stories in 2010/11 when political protests against prevailing systems were becoming more frequent in North Africa and the Middle East, not only giving rise to the aforementioned narrations but presumably also expanding the scope for narrative practices. Wanting to leave "old times" behind as representative of a specific politico-cultural epoch draws on three narrative facets:

(1) Criticism of the epoch which is to be overcome in relation to existing taboos, a lack of freedom of speech and opinion, the discrimination of minorities, and the destruction of natural resources

(2) Emphasis on the wealth of emerging cultural facets alongside or as part of "old times" in the country concerned which should be made visible for the world public as points of reference for social alternatives

(3) Direct or indirect description of an alternative future 
In the narrations, a "better future" is juxtaposed with the criticized "old times," creating the vision which points the way for current actions.

Time and again, the narrators make it clear in their narrations that they are concerned with a collectively experienced past and present as well as a collective future. In order to mark this in their stories, they emphasize a "we" who suffered in the past ("We're talking about many years of suffering, of people suffering") and who should have better chances in the future, as touched on in the statement "the youth of today is the future of tomorrow." The fact that they focus on the past, present, and future in their collective concern is also expressed in the descriptions of their communicative contributions in digital networks as attempts to create a collective consciousness ("We just spread awareness about the importance of litter and recycling") and in their desire to shock society to create awareness of certain points ("The first shock was about my political views and the second is about talking about gender issues and maybe I will also talk about religion").

Another marked element in their narratives in relation to "old times" concerns their designation of the protests in 2010/11 as a revolution, ${ }^{2}$ a wording which was chosen by all of the Arab network actors and bloggers. The term revolution signalizes that the phasing out of "old times" has already begun, not in a harmonious sense but-as the term implies-as a rupture, as a more militant, more violent process. The risks associated with overcoming "old times" are discussed explicitly by those who have made it their goal to do so. The risks to life and limb are described. The experiences of risks invoked in the narratives outline a narrative grappling with the boundaries between "old times" and the alternative future. In all narrators there is a conflict between the recognized need to respect boundaries in order to reduce the risks and their desire to break through boundaries in order to help "new times" to achieve a breakthrough. Contradictory estimates of the boundary line by one and the same narrator indicate that the potential manoeuvrability is being weighed up in their narratives.

The narratives by Arab network actors and bloggers about overcoming a sociocultural epoch help them to refine their analysis of the status quo, to relate their own actions to the perceived status quo, and to plan future steps for action. Their confrontations with the past, present, and future of the societies they live in does not rule out that the stories are also about

\footnotetext{
${ }^{2}$ In the Western media, the "Arab Spring" is the more common term, which implies breaking away but no upheaval.
} 
their own Selves as every life is an existence which is determined by Others and the Other (Straub, 2013, pp. 79-80).

Time is an integral dimension and point of reference in the narrations presented here as told by adolescents and young adults from various countries on various continents. What comes across most clearly in the narrations is biographical and sociocultural time, which is relevant for the narrators as past, present, and future. The past is involved consciously, unconsciously, or potentially as the cause or as a supporting factor while the future is seen as a vision, a dream, or a goal. The present is not named explicitly by the narrators as it is the current context for action from which to view the past and the future and which influences this view. The narrators are too closely associated with the present in order to turn it into an object of reflection.

The narrations have a clearly identifiable middle as expressed in the focus which gives the narrations their name. The narrators often give their narrations a beginning: Sometimes it is defined very precisely, like a particular novel or a particular insight; sometimes it is only described roughly as a time of discrimination or suffering. Often the end of the narration is missing or it is, at best, an imaginary one, such as a successful career as a football player or a society without taboos. The more incomplete the narrations are, the more they allow new elements to be integrated and the more reasons there are for actions involving change. All of the narrations have a progressive character; this means that things are getting better from the narrators' perspective (Kraus, 2000, p. 12). It does not mean that elements of "stability narratives" (2000, p. 12), in which what has happened so far is pinned down, cannot sneak into the narrations or even dominate them. Such elements surface when the narrator's current context of life has become fragile, as was the case with the American student who, far from his family and home town, told about his constant efforts to hold together his family and network of friends by sharing things on different levels.

\subsection{Spatial Relationships}

Questions about space play just as important a role as questions of time in the narrations of the network actors and bloggers. They concentrate on experiencing and managing boundaries, on spatial crossings, and on creating and configuring virtual spaces. 


\subsubsection{Experiencing and Managing Boundaries}

Experiencing and managing boundaries are topics which are mentioned most frequently in the narrations about managing boundaries and in the stories on setting out and breaking away. They are frequently connected with questions on the relation between the public and the private as well as with questions on the relation between virtual and physical reality. The notion of the public is interpreted more broadly here than in the public sphere conceived by Jürgen Habermas, which denotes the space in which free citizens discussed matters of common concern, resulting in a public opinion $(1962 / 1992$, p. 3). The Habermasian concept of the public sphere focuses on the political existence of subjects; in the following, the life-world and autobiographical existence of subjects are also of interest to the extent that they are negotiated in spaces to which there is open access. All narrative practices should belong to the public sphere as long as they are not concealed or secret (Hahn \& Koppetsch, 2011, p. 11).

The Arab network actors and bloggers talk about experiencing boundaries in virtual space as they attempt to set up a critical public sphere online in relation to the sociocultural situation in their region. They are not surprised by the demands they receive to stop their criticism or by threats of violence. Given their attempts to put discursive manoeuvres to the test, they have to reckon with such messages. And yet they are insecure. They then attempt to process this insecurity through narrative. They observe: "It kind of showed me the boundaries!" They still ask: "What are the things that I can do and what are the things that I have the courage to continue with?" They remember: "There is one female activist who was attacked in her house." It is a question of grasping the significance of the indicated boundaries. Which actions can be continued risk-free? Which require courage? Could the same thing happen to me as to the activist who was attacked? Which boundaries do I have to accept? Narrating brings about a reflexive distance which promises to clarify the question as to how virtual space, as part of the public sphere, can be occupied content-wise or how it has to be occupied, despite the risks, in the interests of political goals.

Over and above that, experiencing boundaries is described as experiences taking place on the threshold between virtual and physical space. The narratives of several network actors reveal that limits exist for them on this threshold which should be maintained. A 19-year-old described the situation at a party as "unpleasant" when people suddenly started looking 
at her Flickr album. She was just as irritated when an online friend suggested that they meet up offline. She admitted that she was not sure whether she really was like what she professed to be in the internet. In the first episode, her irritation could have been triggered by the fact that the public sphere online had been extended into a space that she considered to be private. In other words, she had defined a photo shoot as private which she had posted on Flickr as it also included photos of a friend who she had not asked for permission to publish, and it had now been exposed to appraisal from a public sphere which she was part of in this particular situation. In her story she weighs up the advantages and disadvantages of this experience, finally calming herself down, grateful for the opportunity of getting more feedback from other guests at the party, something which she judged to be advantageous. She characterizes the second episode as being a drama. When grappling with the incident in her narrative, it becomes clear to her what the cause of the drama was, namely that in her mind she had always separated "the virtual and the real" and that this separation had been called into question by the proposal to meet up offline.

The Arab blogger who has her own podcast and whose voice is sometimes recognized in real life, for example when she is shopping at the supermarket, would also like to be sure that the dividing line between physical reality and virtuality can be preserved, albeit for different reasons than those of the 19-year-old, who was worried that she had created an online image of herself which did not reflect reality. The Arab blogger wants to attract an audience for the content she posts online but not for herself; whether online or offline, she wishes to remain a private individual.

The narratives about experiencing boundaries indicate that dividing lines between the public and the private, or between online and offline, have started to shift, initiated to a certain extent by the narrators themselves as protagonists. The strict division between the public and the private, which Habermas (1962/1992, p. 28) promoted as a guarantee for the autonomous development of the bourgeois individual, is beginning to liquify. The narratives reveal an interest in clearly defined boundaries, however. At the same time, the narrators struggle with the definition of boundaries which, in view of an absence of regulatory social roles or such roles not being desired, is targeted at extending boundaries, retaining demarcations, or drawing new borders as an independent accomplishment within the framework of given power structures (Jurczyk \& Oechsle, 2008, p. 27). 
The acts which are intended to regulate boundaries are described as strategies for managing boundaries, as discussed earlier for the narrations about managing boundaries. Now they should be categorized systematically. The strategies which were mentioned most frequently include selection and differentiation.

The notion of selection relates to those strategies in the narrations about managing boundaries which are geared towards choosing contents that are to be communicated, or not, or towards people who are to be addressed, or not (Schachtner \& Duller, 2014, pp. 67-68). The Arab network actors and bloggers continuously mention social taboos which they want to, or have to, avoid in their posts, albeit interspersed with comments that they actually would like to talk about such matters and whether they should not talk about them anyway. Both the Arab and Western network actors and bloggers describe how they withhold personal details like what they are called and where they live; they would like to carry on an unidentifiable existence beyond the internet. They explained that it was in the interests of their safety to do so, but the opposite conclusion can also be drawn, namely that they want to safeguard their freedoms online. Above and beyond that, the narrators wonder about the group of people they are addressing, like this 12-year-old, who explained: "I'm also careful about who I write to. ... I only write to real friends anyway who I know for real." This "for real" refers to face-to-face contacts which should guide her choice of digital communication partners. On the narrative level, physical reality appears to be the more trustworthy kind of reality in the sense that it provides reliable information about the Other.

Alongside strategies of selection, strategies of differentiation are also mentioned which are used to compartmentalize virtual space as characterized by different degrees of public sphere-ness (Schachtner \& Duller, 2014 , pp. 68-69). One act of differentiation consists of assigning a particular status of public-ness to existing online networks, for example when Facebook is reserved for contacts with family and close friends while other networks are used to contact acquaintances or to come into contact with an anonymous public. Another differentiation strategy which was talked about consists of creating virtual spaces which are assigned different degrees of public-ness, as in the case of the Arab blogger who talked about her three blogs, aimed at her family, the regional public sphere, and an international public sphere.

All of the strategies about managing boundaries identified in the narratives are geared towards defining clear boundaries between the public and 
the private, or between virtual and physical reality. The boundaries drawn in the narratives vary as they rely on individual acts. It also comes about that the private and the public are assigned to different locations and even that they are freed from being tied to a specific location, becoming a perspective of the subject that establishes the private in the very heart of the public (Jurczyk \& Oechsle, 2008, p. 17), as with the blogger who reclaimed her private sphere right in the middle of a supermarket.

The narrators' strategic deliberations on managing boundaries are accompanied by feelings of doubt, anger, and insecurity, as well as by selfrecrimination and fear. While one blogger asked whether she had drawn the line between the public and the private to the detriment of the latter ("Whether I should have actually disclosed that?"), particularly in view of her network activities at the age of 14 , another one wondered whether she had reduced the scope of the public sphere too much when she deleted a post on her blog after being criticized by members of the public online ("I wish I didn't delete it.").

For Geert Lovink, the collective "confusion over ... how much we should reveal about our private lives and opinions is on the rise" (2011, p. 39). Should this trend be confirmed, it is not only because individuals are left to their own devices when restructuring the relationship between the public and the private, but also because "sophisticated tracing technologies ... have effectively destroyed online anonymity" (Lovink, 2011, p. 47). What is more, the internet never forgets. Mistakes which have been made, as many know to their cost, are not easy to fix, or as a male network actor from Saudi Arabia put it, "[i]f you post them [pieces of information], they are gone [posted] for ever, even if you delete them, they're gonna be there."

\subsubsection{Spatial Crossings}

Spatial crossings are another facet of spatial relationships addressed in the stories of the network actors and bloggers. Tales are told of both communicative and physical crossings.

The communicative crossings are hardly surprising, recounted as they are by network actors and bloggers who are using a medium which counts interconnectedness and globality amongst its structural characteristics. Spaces are crossed with every post and every tweet, but this is only thematized in the narratives when digitally assisted communication goes beyond national borders and across continents. "I'm talking to the world" is what 
they want to get across. The experiences associated with communicative spatial crossings are described as representing diversity and differences. Diversity is illustrated by the different communication styles and opinions, which also have something to do with alternative ways of thinking, as an American student established. Diversity then brings differences to the fore as comparisons are virtually unavoidable, especially when misunderstandings arise. In the narratives, attempts are made to characterize diversity and differences as well as to relate them to the Own. The fact that this does not stay on the surface for the narrators is clarified by a network actor from Saudi Arabia: "I cannot determine what is the difference of impact that I'm taking from everywhere else coming back into me." Diversity becomes part of his personality, as long as he remains on the stage which is the internet at least, where he experiences himself as being "multinational" and "multigeographical." The prefix "multi" implies that the many exist alongside each other. Another network actor, who does not only communicate and cooperate digitally with partners from all over the world but who has also lived in several different countries, has coalesced into a hybrid whole, as he explained: "I'm a citizen of the world, like I could be at home just everywhere." Salmon Rushdie characterizes the crossing of boundaries, which, for him, implies the crossing of space and the Self, as new life forms: "The migrant, the man without frontiers, is the archetypal figure of our age" $(2002$, p. 415).

Experience of differences is also described as a key experience in the narratives about physical spatial crossings, but here it is not intrinsically characterized as being enriching and stimulating. In his story about setting out, the Turkish student who had moved to Vienna on a student exchange approaches day-to-day life, which differs so much from that in his home country, with scepticism, asking whether he can find the familiar in it or whether he will remain excluded from this day-to-day life. In her story about setting out, the American globetrotter who had been travelling through Europe for three to four years at the time of her narrative refers to the many different day-to-day lives which she has been confronted with on the European leg of her journey and which appear to promote a fragmentation of experiences, at least when identifying potential reasons from her attempts to link up her everyday experiences through images.

Whereas the internet is characterized as a corrosive medium, wearing holes in closed systems in the case of the communicative spatial crossings, it is seen as a constructive medium in connection with the physical spatial crossings, for example in attempts to establish contacts or in the digital 
photo galleries. In any case, Assmann is surely correct when she writes: "Those who have crossed the frontiers from one state, society and culture to another have a great deal in common with those who have crossed the frontiers of familiarity, tradition and perception" (2012, p. 215). The social consequences of the type of spatial crossings named by Assmann are described by the narrators involved in this study as being not only enriching but also unsettling and threatening.

\subsubsection{Creating and Configuring Spaces}

Starting from a hybrid notion of space (Maresch \& Werber, 2002, p. 13) according to which spaces are composed of material and immaterial parts, the narrations of the network actors and bloggers reveal numerous attempts to create and configure a space in the internet through their narrative practices. These narrative acts are portrayed implicitly or explicitly in the narrations. On the broad spectrum of spaces produced through narrative, the ones which stand out most clearly in the narrations include spaces for political discourse, selling, training, and flirting.

The spaces for political discourse appear in the stories about interconnectedness as well as about setting out and breaking away in so far as they are told by Arab network actors and bloggers. They generate this type of space by describing social platforms as locations for exchanging political analyses and opinions, for breaking social taboos, for supporting discriminated minorities, and for organizing political activities. In addition, the narrations include references to the risks which beleaguer these spaces and to attempts to reduce these risks, whether by leaving out certain topics or by redefining political discourses as cultural or social discourses.

In the narrations about suppliers and sellers, virtual salesrooms are created when talking about internet practices which focus on the provision of services, products, recommendations, and projects. As protagonists of these practices, the narrators promise themselves financial and ideational gains like acknowledgement, belonging, and solidarity.

In all of the narrations, virtual space is characterized as a location for training, either implicitly or explicitly. The 24-year-old Arab network actor who declares that "Mideast Youth is education" expresses it directly. For her, education means scrutinizing everything. The 12 -year-old network actor who regards the social SWR Kindernetz portal (2020) as a space in which she can improve her drawing skills speaks out just as explicitly. Other narrations provide insights into the training of a whole set of 
other skills like coming to terms with social conditions through images, creating self-representations as blueprints for the future, reconfiguring boundaries, overcoming patterns of childhood behaviour, and anticipating the needs of Others, as well as developing leadership ability, organizational capability, communication skills, and a capacity for interconnectedness.

Virtual space also appears as a space for flirting in the narrations, although not as frequently or as clearly as might be assumed from other studies (Illouz, 2007, pp. $75 \mathrm{ff}$.). Only the narrations about self-staging and transformation related by adolescents have some references to this type of space. It acquires clearer contours when the 11-year-old says that he is more likely to dare to contact girls in virtual space or when the 12-year-old describes a boy's attempts to "chat her up," to which, naturally, she turns a deaf ear. In the descriptions of self-staging there is more potential for flirting when these enactments are identifiable as being oriented towards ideals of beauty which are geared to the opposite sex. The weak manifestation of virtual spaces for flirting in the narrations does not mean that they do not exist; this can also be due to the context in which the narrations were related, namely as part of a research environment in which the narrators drew lines between the public and the private and in which the researchers did not explicitly take up the topic of erotic relationships in the internet.

Thanks to digital media, experiencing boundaries, spatial crossings, and configuration of space have gained new facets of meaning. Spaces in the physical world are enlarged or complemented by new virtual spaces which are open to contents of all kinds but which also pose questions as to their relationship with spaces beyond the digital world. New public spheres arise which are used with great enthusiasm but which also meet with resistance, from the forces of law and order, for instance. Boundaries liquify or are redrawn by the network actors themselves or by other actors. The narratives address changes to space assisted by the media as well as options for new spatial structures which condense into individual projects; for the time being, however, that is what they remain: the projects of single individuals.

\subsection{Representations of the SelF}

The thesis formulated in the second and third chapters of the book with reference to Foucault that narratives constitute themselves as technologies of Self-construction has been confirmed as a general trend in the analysis 
of the empirical data. One result of this constitutive act is that selfrepresentations are revealed in which the following dimensions have a key role to play: standardization and experimentation, orientation, and division and continuity.

\subsubsection{Standardization and Experimentation}

"Hot cultures," which include Western industrialized countries, "embrace invention and alteration" and even non-conformity (2012, pp. 118-119), as Assmann observes with reference to Lévi-Strauss (1962/1966, p. 233). The eagerness to experiment online in relation to one's own I which the adolescent network actors and bloggers from Western countries relate in their stories appears to be an expression of culturally promoted nonconformity. Here is the 21 -year-old who wants to catapult herself into a fearless existence with the help of her nickname, Gaia, with the promise of independence and an ability to master the turning points in her life. Here are the adolescents who are engrossed in digital role-playing games, whether it is a small boy wanting to become a famous footballer or a 12-year-old girl slipping into a Self which appears to be contrary to their own Self or which involves taking on a different gender. Through their narrative acts in the internet which they refer to in their stories, everything speaks in favour of these network actors and bloggers setting their sights on a Self of the sort that Assmann calls an "exclusive identity" (2012, p. 200), which should distinguish the I from prescribed roles, emphasizing that the I is completely different from all Others. As strong as this wish may be, this begs the question as to whether the self-experiments they undertake really are major experiments in defiance of what is prescribed. Do fearlessness, superiority, and independence not also represent what society expects of them? Do fame and the flexibility of the individual not count amongst the honoured values of contemporary society (RothEbner, 2015, pp. 310ff.; Sennett, 1998)?

In the stories told by Arab network actors and bloggers, who live in socalled cold cultures in which there is resistance to change, in which the signals point to cyclical repetition, and in which an "inclusive identity" is prescribed in conformity with traditional roles, there is a clear "no" to performing such "preformulated social roles" (Assmann, 2012, p. 200). In their stories a rebellious subject is conceptualized which declines to defer to society's expectations, which is in conflict with traditional expectations, which formulates alternatives, which is willing to take chances, 
and which, time and again, has to concede that there are unsurmountable boundaries which cannot be ignored in order to protect themselves.

For Lovink, the trend towards standardization dominates Web 2.0, engendered by a global monitoring and surveillance industry which does not exactly encourage experiments with the I and one answer to which is the "Religion of the Positive" (2011, pp. 43-44). Indeed, this religion crops up in many narrations, for example when individuals explain how carefully a self-portrait is edited before being posted online in order to create a beautiful image for oneself and the Others or when they admit that sad and negative elements are excluded from posts in favour of communicated cheerfulness. Of course, not all narrators want to restrict their existence in the net to positive matters alone; some of them also want to reveal their dark sides. And even with those whose digital self-staging is guided by prevailing standards of beauty, flaws can be revealed, as this visualization illustrates in which a blogger draws attention to her online existence (Fig. 5.1).

Long hair, cupid lips, big eyes, round female forms, and shopping bags indicate conformity to current ideals of femininity and female beauty which are presented to a gaze for its perusal. But then there are also accessories in the drawing which symbolize divergence from this stereotype. A camera, paint brush, and pen represent her professional ambitions, standing for her desire for self-determination, individuality, and independence.

Seldom are such narrative self-representations unambiguous, whether in the form of images or texts. Mostly, they move between the opposing principles of standardization and experimentation, striking out for this pole rather than that, although that can change too, for one thing is clear: The self-representations are porous, open constructs. Narrating proves to be a technology of enablement and subjection, bringing about a double life as subject and sovereign in which variations are possible but offer no escape from social dependency.

\subsubsection{Orientation}

Orientation is about defining one's own position within a specific social context and, on the basis of this definition, being able to develop perspectives for the future with implications for acting. That presupposes knowledge of the Self and of the world. Both arise from the interpretation of experiences which individuals make and have made with themselves in their interactions with the social and cultural world which surrounds them. 


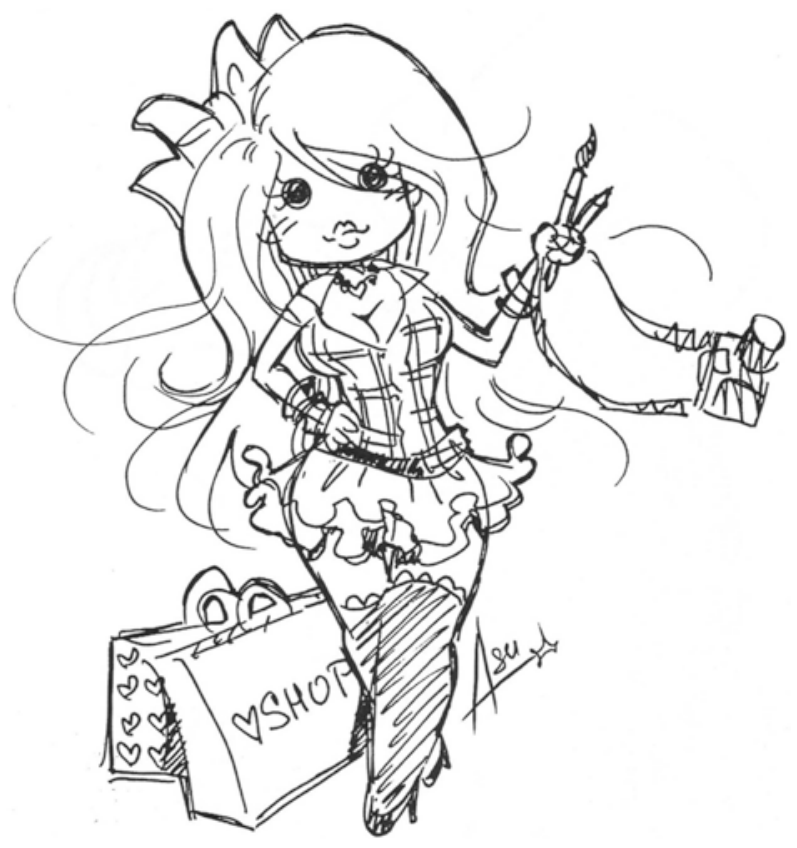

Fig. 5.1 Standardization and experimentation (blogger, f, 24, Germany)

The past, too, both autobiographical and sociocultural, needs to be interpreted if it is to expand the horizons of their understanding. It is the stories, the big and the small ones, in which people search, interpretatively, for themselves and the world. This quest grows all the more volatile when existing orientations become obsolete, when confusion arises, and when there is a dearth of possible courses of action. In times of upheaval, insecurity is intensified. And so it is hardly surprising when questions of orientation are particularly obvious as a dimension of narrative self-representations in those narrations in which biographical and sociocultural upheaval form the context for subject construction, namely in the narrations about transformation as well as about setting out and breaking away.

Indications of a quest for the Self are found in the narratives by adolescent network actors and bloggers which are about searching for role models or searching for the right thing, which are about things to do with media technology and fashion labels with which they want to demonstrate 
or secure their status, or which are about access to different online applications and websites which establish their position en route to adult life.

Quests for orientation in the sociocultural situations of upheaval find expression in a critical analysis of the social status quo, in experiments which involve breaking social taboos, in the development of social alternatives, and also in the to and fro between rebellion and remaining silent in the narrations of the Arab network actors and bloggers.

The options for defining one's Self and the world depend on narratives being laboratories in which their narrators can analyse, compare, categorize, and look for solutions. In narrating, Straub believes, subjects gain the necessary reflexive distance to what they have experienced which is constitutive for the establishment of orientation (2013, pp. 104-105) but which does not necessarily protect them from errors of judgement. That does not speak against their narrative quest for orientation. Even when this quest is risky, it is one of the most important possibilities for individuals to affirm themselves and the world.

\subsubsection{Division Versus Continuity}

When virtual spaces are used as locations for activity or as showrooms, the practices associated with these intentions are decisive in relation to who we want to be in these locations, bearing in mind that what we do is an essential part of who we are. "Who am I online?" is a question which the narrators pick up on spontaneously, more or less intensively, during their interviews. At the end of every interview, this question was then posed explicitly by the researchers, along with a request to give an answer to it in the form of a drawing. One of the answers to this question gave rise to the picture portrayed in Fig. 5.2.

Here we can see what the 22-year-old calls a "two-part portrait." She characterizes one side of her face as "pompous," that being the online side, whereas the other side is "simpler" and "more human," that being the offline side. Apart from being able to take the portrait as proof of the "Religion of the Positive" (Lovink, 2011, pp. 43-44) which is prevalent online, it also illustrates the phenomenon of division, which has its counterpoint in the phenomenon of continuity, which finds its voice in other stories. Division and continuity play a key role in the narrative Selfconstruction of network actors and bloggers, which was already hinted at in the strategy of selection as a form of managing boundaries. In what follows, not only should individual practices of division or continuity be 


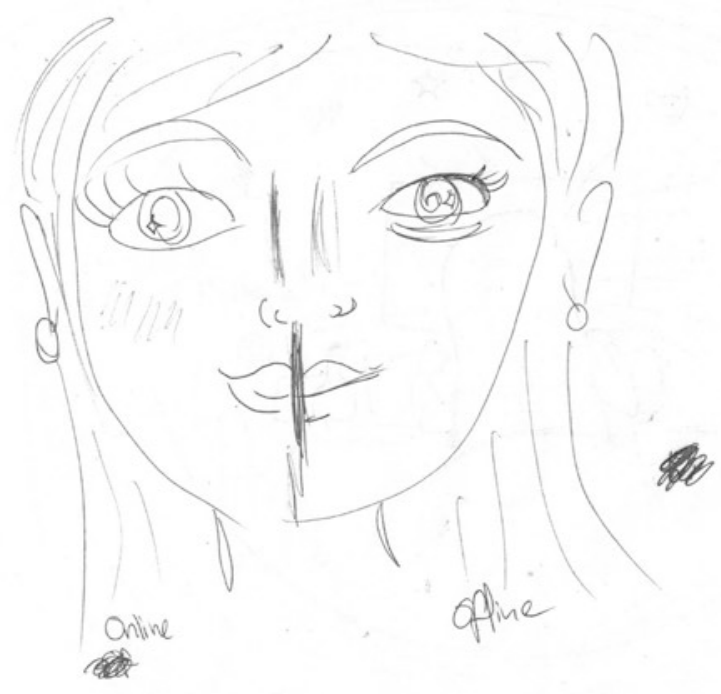

Fig. 5.2 The two-part portrait (blogger, f, 22, Germany)

considered but also how the subjects position themselves as a whole between the opposing principles of division and continuity.

Just like the 22-year-old German blogger, a 24-year-old Arab network actor also divides up her personality into an online and an offline version. In contrast with the former, according to her narrative, she does not post any touched-up photos of herself online; in fact, she does not post any images of herself in the net. Her visual presence is reserved for the offline world while online she is present through her argumentation, which does not happen offline. "On Mideast Youth I am much more outspoken I would say than I am in real life," she explained, continuing that the cause she championed in the internet, namely the rights of minorities, was not a topic that she would pursue in the world beyond the internet. In her own words, "I'm not going to go out in public and hold the microphone and say, 'I support gay rights for everyone'." This division did not only relate to the topics but also to the way in which she expressed herself. She reckoned that her language online was more powerful and aggressive. In response to the question "Who am I online?" she drew a woman wearing a niqab where only her eyes are seen. Her comment: "It's just to show that 
who I am online is different than who I am offline." Her observant, critical gaze is visible in the public sphere online while her body is not. In the public sphere beyond the internet, in contrast, the body of the network actor is visible, albeit veiled, but not the political stance arising from her critical analysis. Accordingly, the link between body and politics frames what the network actor attempts to avoid.

Both examples of division are due to assumed dangers, in the first case, fears about dangers relating to the blogger's private life, and in the second, danger for life and limb, which might not be directed at the network actor alone, as she related, but also at her family ("There will be consequences suffering by my family").

Narrations which are about division contrast with narrations which are about continuity. An example of the latter is the self-staging narration of the 23-year-old blogger from Austria who blogs about fashion and his feelings. In his interview, he declared: "My blog mirrors my personality." For him, it was important, he recounted, to let his personality live on in the internet and to show everything it amounted to beyond the internet, including tragic moments in the form of emotional states after splitting up with a partner. His narrative does not reflect the "Religion of the Positive" but maybe a different religion, the religion of being oneself, proof of which can be found in the fact that the cracks in the beautiful image are blogged about quite candidly.

The 27-year-old blogger from the Arab world who presents a narration about managing boundaries spoke even more directly about continuity being a dimension of her self-representation when she commented: "I feel like my life online cannot even be separated from my, like, real life. It's mostly like a continuation." Whereas it is feelings which bring about continuity for the 23-year-old blogger, it is interests, hobbies, and friends which guarantee continuity for the 27-year-old Arab blogger, as she said: "Everything that I do online has a connection to what I do in real life. My interests, my hobbies, my friends-it's all very much interconnected."

In order to describe division and continuity as dimensions of selfrepresentations, I have selected narrations which clearly illustrate the two extremes. Many other narrations fluctuate between the two. But the case studies discussed earlier also include fractures. The 27-year-old Arab blogger is the one who denied her online existence in the supermarket, as described in Sect. 4.4.1, at which point she was not counting on continuity but rather on division. Conversely, the 24-year-old Arab network actor who was strongly in favour of division described how she had started to 
give her full name online, making it possible to associate her offline existence with her online presence. This could have to do with the fact that she has become so well known, also in Western media, that her name offers her more protection than her anonymity.

Division and continuity are opposing trends which have a flexible relationship with each other and where decisions have to be made constantly about maxims for future action in the light of new experiences.

\subsection{Connections with the You}

Whether the narrations of network actors and bloggers are about time stamps, spatial relationships, or self-representations, the I does not act in isolation in relation to time, space, or the Self; there is always a You involved. This You appears on the narrative stage as a concrete reference point, a topic in the narration, or in the imagination. It is not possible to explore all of the subtle ramifications of I-You relationships which run like a golden thread through the narrations. Instead I will limit my discussion to two phenomena in the I-You relationship which can be seen as typical of the net generation, intertwined as these phenomena are with the opportunities offered by digital media: wrestling for the Other's attention and the You in world communication.

\subsubsection{Wrestling for the Other's Attention}

"My entire blog is simply a challenge for me to get as many comments as possible and as many readers as possible," explained a 14-year-old blogger from Germany. The interest in comments and readers comes up time and again in the narrations, regardless of the age, gender, and cultural background of the narrators. An entire arsenal of strategies and efforts is deployed in order to ensure the Others' attention:

- Taking the greatest of care when writing articles, which are reread and corrected the next day before they are posted online

- Ensuring accuracy and reliability when reviewing products

- Reading other blogs to win their authors over as readers of one's own blog

- Regularly writing posts, even when it is a challenge to do so 
The publication of one's own posts, articles, or "micro-narratives," as Ries calls them, takes place in full knowledge of the fact that "the addressees do not only read, observe, and hear but also write themselves, make films, and distribute music" (2013, p. 34). The narrators in the internet produce for other narrators, expect to get their narrative fragments in return, and produce new ones themselves $(2013$, p. 34). Being part of the lives of Others and having Others being part of one's own life are described as being important objectives. "I perch here permanently ... waiting for somebody to deign to let me be part of their lives" was how a 29-year-old network actor from Austria put it (cf. Sect. 4.1.2), his comment expressing the ambivalent feelings that he appears to have in view of his dependence on the Other. This cycle of publishing and waiting has turned into a "drug" for him, he continued.

Lovink talks about a "comment culture" (2011, pp. 50ff.) in digital networks whose credo is "please say something about me, transport me further, link to me, like me" (2011, p. 59). According to him, "comments circulate around the ... source text," they appear "informal, fast, and fluid," they "bring the silent original to life" (2011, p. 55), and in so doing invigorate the author as well, as a sign of affection.

"I never turn my computer off. Even in the middle of the night it's always on in case something, somebody calls me like so I can get it," recounted the 24-year-old American who was touring through Europe. As reported by other network actors and bloggers as well, the desire for attention results in the boundary between online and offline being overridden, or in virtual and physical spaces being permanently interlaced with each other, either because the laptop or smartphone is never switched off or because the devices are even taken to bed so that first thing in the morning, it is possible to dip into the world of virtual contacts, as a 21-year-old network actor from the United Arab Emirates described: “As soon as I wake up, I roll over [laughing] and even though I can't see properly, I type in all my passwords to my e-mails, check my e-mails." Should the expected messages, comments, and feedback not turn up, it is possible to force them to happen, as a 29 -year-old depicted it metaphorically:

You have a fishing rod with 200 fishhooks and one of your friends is hanging on every one of those hooks, and whenever you need one of them, you fish him out of the pond with the other 100,000 fish in it. 
The interactive character of the medium makes it possible for individuals to become active themselves; above and beyond this, it creates the illusion of a practically unlimited number of Others who can be accessed.

What is the rationale behind the consistently keen interest in telling things to each other and narrating? There is the matter of undeniable dependence on the Other, as set out earlier with recourse to Meyer-Drawe (1990) and J. Benjamin (1988), who can see parts of us which we cannot see ourselves as we only ever see fragments of our whole. Then, as Mead taught us, there is the necessity of the Other as the "generalized other" (1934, p. 154), who confronts us with social norms against which we can read off the degree of our compliance or non-compliance. Safeguarding the Other in this sense is embedded in the modus operandi of giving and taking; I have to turn towards the Other so that the Other turns towards me.

Ries believes that the exchange of everyday micro-narratives online has also got something to do with the silence of the world and its systems $(2013$, p. 39). What he understands by this silence is the invincibility of nature and individuals' failure to get to grips with this social world by dint of which they are no longer in control of their lives (2013, p. 39). With their digitally assisted speech acts, reflecting everyday life, they assert their territorial links and the fact that they are not alone "versus the silence of the systems and the institutions" (2013, p. 40).

The comment of a 29 -year-old that he was afraid of being "left out" if contact was severed with the Others provides a third reason: fear of no longer belonging, of being sidelined, of no longer being seen. In her novel The Sorrows of an American, Siri Hustvedt formulates this fear as the general fear of humans today: "'So few people look at you,' Burton said. 'Blind and deaf public hordes with shopping bags and briefcases and backpacks pass you by-that is the lot, my friend, of the unseen, the unknown, the unsignified, and the forgotten"” (2008, p. 291).

The fact that wrestling for the Others' attention in the digital media has become so intense is not due to the need for the Other having become stronger but rather because these media, as networked media, symbolize not only the promise of the Other but also the fulfilment of this promise.

\subsubsection{World Communication}

For him, it was clear from the very beginning, recounted a 26 -year-old network actor from Saudi Arabia, who first got to know the internet when he was 13 years old, that " $[\mathrm{t}]$ here is something very big out there. It's not 
limited to us." He recognized the potential of the internet in the opportunities to spread ideas beyond national borders. For him it was the prelude for interaction between Saudi Arabia and the international community.

The internet is a technology, according to Ries, which opens up the opportunity for tweets, posts, and images "to be produced, heard, and seen by many via the medium" (2013, p. 32). World communication becomes possible for everybody as long as they have access to these media and have the necessary communicative competences at their command. It is no longer reserved for the privileged few in politics, business, academia, and art.

World communication is visible in the narrations in different forms and has different meanings for individual narrators. The 26-year-old network actor from Saudi Arabia described how he made use of what he perceived as the communication potential of the medium in order to build up a worldwide network of friends in which events from different parts of the world could be discussed. This enables a global commentary to develop, as it were, which feeds on input from all four corners of the earth. As a second form of world communication, he depicts his attempts to introduce a version of Saudi Arabia to the world (cf. Sect. 4.1.1) which would otherwise remain concealed from the global public. Almost all of the Arab network actors and bloggers talk about this kind of world communication which should change the image of their countries and its culture as conveyed by the state-run media.

Thanks to digital media, worldwide communication has experienced an upswing the likes of which has never been seen before, which has led media theorist Norbert Bolz to propose that our perception of the world is identical to our perception of communication (2001, p. 7). Neither in his proposal nor in the examples of world communication mentioned earlier has communication merely played an instrumental role; it also leaves its mark on the contents of our perceptions and changes images.

Alongside the political ambitions which stimulate world communication, there are personal reasons too, as illustrated in the self-staging stories, for example. When the 23-year-old Austrian blogger said that he wrote his blog in English, it is surely not only due to his being more comfortable writing in English, as he claimed, but must also be connected with his aspiration, as a fashion expert, to be appreciated beyond national borders, which he describes as his goal at a different point in the interview. Knowing that they enjoy global visibility in the internet is seized upon by 
all of the network actors and bloggers who told a self-staging story. As self-staging does not make sense without an audience, it can be assumed that the self-staging network actors, in the spirit of Lacan, are "call[ing] for a response" (1953/1996, p. 206), that they want to trigger off reverberations which would surely not be unwelcome as a global reverberation.

As the types of information and communication technologies continue to expand, these ties via the media "extend around the world" (William J. T. Mitchell, 2003, p. 17), as do our social relationships; the formats of perception and communication extend and change too. The miniaturization and merging of the digital devices which have made their way into our pockets and handbags ensures that we can stay more or less in permanent contact with the world. This changes subjectivity, "tak[ing] us another step further away from the Edenic condition of living entirely in the here and now, and allow[ing] homo electronicus endless shifts of attention and engagement throughout the reaches of space and time" (William J. T. Mitchell, 2005, p. 185).

\subsection{Narrators, Narratives, Media: Cornerstones OF INTERPLAY}

The references to space, time, the Self, and the You identified in the narrations of the network actors and bloggers always include references to digital technology as well because the narrators' lives are enmeshed with this technology. The interplay between narrators, narratives, and media technology is multifaceted. The distinctive cornerstones of this interplay, around which individual media references cluster, are the centre of attention in this section.

\subsubsection{No End in Sight}

Even though only one network actor explicitly describes the notion of sharing as the goal behind his narrative activities in the internet, all narrations point to the sharing of messages, images, and videos. Ries suggests that the act of sharing results in narrative migrations online which "turn up, are imparted, and are shared simultaneously in different places" $(2013$, p. 36). It is the structure of digital networks, in connection with the subjects' intentions, which gets the narratives up and running. 
According to Hartmut Böhme, networks are organization forms for producing, distributing, and communicating objects of a material or symbolic nature $(2004$, p. 19). As computer-assisted networks are heterarchical (2004, p. 32), there is no one central body to steer such migrations. Their anarchic character is at least peculiar to the technical structure of digital media, but we also know from the narratives that there are attempts to conscript hierarchical elements into the technology. Despite such attempts, the internet is still spoken of by many as a place which "evokes, without restraint, textual, photographic, and film productions as raw materials for its exchange scenarios" (Ries, 2013, p. 41). The raw materials which the scenarios provide make it possible for discourses, acts of self-staging, and photo galleries to change constantly, taking up or omitting elements, redeploying one's own I and its speech acts in an apparently endless state of dynamism.

This dynamism is reflected in the narrations which report on the distribution of communication via digital services ("I tweet, I blog, I skype, I sms, I ...") or which describe sauntering discursive movements across continents. It is expressed in the attempts which are described to reshape one's digital presentation of the Self time and again, motivated by the interactive exchange with Others, or to split up this I into different roles which represent and refine different facets of this I in different media settings. It can be read in the narratives on the never-ending canvassing for readers and followers, connected with hopes of an unimaginable number of comments. No end in sight is one way of summarizing the imagined character of the developmental potential of digital networks. The network as a building site (Böhme, 2004, p. 33) manages wishes and hopes but can also generate disquiet, as in the narration related by the Turkish student who, on arrival in a new cultural setting, doubts whether he can make new friends there. In this case, it illustrates the emotional processing of the possibility that the anticipated dynamics in the internet which bestow new friends on the narrator could come to an end. Other narrations bear witness to the emotional processing of the endlessness ascribed to the internet. The feelings which are described oscillate between delight at unprecedented opportunities for freedom or a wealth of options and annoyance at the self-imposed pressure of never being able to stop the hunt for new options.

As mentioned earlier, there are attempts to conscript hierarchies into the heterarchy of digital networks which work against the infinite number 
of options. They are embodied by administrators, network providers, and, above all, by increasing instances of control and monitoring worldwide, which often work in tandem with political systems. At the same time, counterforces can be observed which emerge from the ranks of network actors and which defeat the modern controllers with their own means with the help of intelligent technical constructions and creative strategies. Further counterforces arise from the rhizome-like character of digital networks. Should it be true that these networks have a rhizome-like character, as postulated in Sect. 3.2.1.4 ("Dynamics"), it will also become difficult for that reason to inhibit the proliferation of narratives because such networks overcome interruptions, for example due to censorship, to reemerge at another point in time and maybe at a more sheltered spot.

\subsubsection{The Upswing of the Image}

Images, like words, are objectivations of human practice and, as such, embody meanings. Images count as presentational carriers of meaning which, in contrast to verbal language, do not arrange units of meaning one after the other but are "understood only through the meaning of the whole, through their relations within the total structure" (Langer, 1957, p. 103). Until the 1980 s the image was considered to be a qualitatively less valuable carrier of meaning in comparison to verbal language, amongst other reasons because images address the feelings and senses immediately. Going back to Greek philosophy, emotions and senses represent, as John Dewey sets forth, the unstable, arrested desire, or permanent change, which, unlike thinking, discourage us from apprehending the essence of things (1916/2009, pp. 449ff.). Krämer and Bredekamp, too, point out that "for a long time, perhaps for too long, culture was seen only as text" $(2003 / 2013$, p. 20$)$. Grasping the world of culture as a "world of discursive signs" $(2003 / 2013$, p. 21$)$ is deep-seated indeed in Western tradition. Digital media, too, were exclusively text-based media to start with; even the first computer games like MUDs ${ }^{3}$ were based on text. The dominance of verbal language in virtual spaces has been crumbling, however, since digital media started developing into multimedia which integrate text, image, and sound. The narrations of the network actors and bloggers corroborate that, alongside text, sound in the form of podcasts and music but

\footnotetext{
${ }^{3}$ An MUD (Multi User Dungeon) is a text-based role-playing game running on a central server which several players can log into.
} 
above all the image has gained in significance. What functions of the image emerge out of the narrations, whether implicitly or explicitly?

The function of an image as a document is illustrated in the interconnectedness narration of the 26-year-old blogger who was born and grew up in Switzerland and later lived in various countries in Europe as well as in North and South America. At the time of the interview he was living in Saudi Arabia. As mentioned in Sect. 4.1.1, he produces photos series for his blog which visualize social questions like refugee issues and violence but also the types of clothing worn by Arab women. His narrative on these photo series includes the information that he had already been attacked verbally on several occasions for taking photos. His reaction to these attacks is one of bewilderment because he sees himself as an external observer with a neutral gaze. But presumably, under the impression of the various cultures he has lived in, he has developed a distinct eye for a shot, content-wise, which has an influence on his perspective as a photographer and which is in conflict with the norms of the country he is currently living in. One consequence of this gaze could be that the meaning of the photos he takes transcends the superficial purpose of documentation, which pictures tend to do anyway according to art historian W. J. T. Mitchell (2005, p. 31). The 26-year-old is wise to the excess of meaning, commenting that his photos of full-body veils worn by women show that the traditional attire of women in Saudi Arabia has turned into a "sexy thing." Accordingly, his photos point to a sexualization of clothing, invoking a taboo which surely did not go unnoticed by those readers or observers of his blog who criticized him for the photos he had posted.

In connection with the production of his photo series, the 26-yearold called himself a "community photographer," which implies that these series do not arise from the activities of one person alone. $\mathrm{He}$ described how he follows the photo blogs of other bloggers from which he gathers inspiration for his own photo blog and, at the same time, relates his images to the images of Others. As already described in connection with written posts, the production of images appears to take place with an awareness of the productions of Others. Mutual inspiration is not reserved to virtual space, of course, but it makes the process easier and quicker whereby images and texts become a kind of joint effort. It is not coincidental that there are tendencies to waive individual authorship for media products. 
Moreover, images can prove valuable as binding agents, so to speak, as recounted by the 21-year-old American in his interconnectedness narration and the 24-year-old American in her setting-out narration. In the first case, the images of everyday activities serve to set up links between people who live some distance from each other ("Look at my Facebook profile at these photos today, you might enjoy them"). In the second case it is a question of linking experiences related to different places ("I take pictures of my food that I eat in different countries"). The narratives which bring the image into play as a binding agent say something about the narrators' attempts to establish coherence. People, situations, and experiences all want to be linked to each other so as to strengthen the feeling of living a coherent life, something that is imperilled by mobility and shorter-term commitments these days. Selecting and arranging images from particular subject areas-whether journeys, birthday parties, visits to the zoo, or family excursions - can create a coherent image of a person according to Nünning (2013, p. 163). This feeling of coherence is not limited to the individual posting the images online; it can also be presented to the outside world, giving the impression of a coherent life to those viewing the photos.

A third function of the image is revealed in the self-staging narrations. Here the narrators mention not only images but also texts as means of portraying themselves, but the image-in the form of profile photos, photo galleries, videos, and drawings - is accorded a much greater significance for the narrative. Part of these self-staging narrations includes giving detailed descriptions of the production of such images as a project in which appearance, facial expressions, gestures, and pose are very carefully staged and later edited, very much in the sense of technologies of Selfconstruction. The narrators make it clear that the body which is translated by these images "into media forms, the acting, self-portraying, masquerading, morphing body, the performing body becomes more attractive when used as an image" (Ries, 2013, p. 41). The body as an image wants to be admired, envied, and discovered; it should safeguard social contacts and future prospects. As the protagonists of these body images, the narrators find them important on two counts, as their stories reveal: the consistency of the image and signalling the flexibility and changeability of this image (Nünning, 2013, p. 159). Thus a body comes into view which sets continuity and discontinuity in a dynamic relation to each other. 
Lorenzer's theory that words can never be as closely associated with visible objects as images can (1981, p. 28) could be extended to propose that wishes and dreams may be much more closely associated with images than words could ever be. Is that why the competition between text and image operates to the benefit of the image? If nothing else, under the influence of the multimediality and globality of digital media, a woven carpet of images could arise in connection with the image-producing subjects which pushes the word into the second row. In "The Relationship Between Language and the Image" (Sect. 3.2.4.3), I already mentioned the "pictorial turn" (W. J. T. Mitchell, 1994, pp. Ilff.); to this can be added a "visual culture," which is in the process of superseding textual culture. This trend does contrast with another development, however, in digital networks and on websites, at least, where the boundaries between text and image are liquefying and where novel text-image constructions arise from which the hierarchy has been removed in favour of a subtle word-image-sound combo, which is often comical to boot (Reichert, 2013 , p. 529).

\subsubsection{Transmedia}

As already mentioned in "The Narrative Potential of Digital Heterotopias" in Sect. 3.2.5.3, transmedia is a concept introduced by media scholar Henry Jenkins which he defines, very briefly, as follows: "Transmedia, used by itself, simply means 'across media"” (2011, para. 8). Jenkins already recognized the narrative potential of transmedia trends; he also coined the term "transmedia storytelling," which describes "one logic for thinking 4 about the flow of content across media" (2011, para. 8).

Transmedia narrating is embedded in the flows of communication, information, images, and sounds which extend across different media. Transmedia is a growing topic in narrative research: It deals with transmedia productions in which stories told by media companies are staged as transmedia happenings which can partially be co-constructed interactively by the addressees. The first transmedia project of this type in Germany was Alpha 0.7, a science fiction thriller series on TV and the radio as well as in the internet (Söller-Eckert, 2013, p. 350).

4 "We might also think about transmedia branding, transmedia performance, transmedia ritual, transmedia play, transmedia activism, and transmedia spectacle as other logics" (Jenkins, 2011, para. 8). 
In this section I am not using the term transmedia for media productions organized by media companies. My research interest focuses rather on the transmedia narrative projects initiated by the network actors and bloggers themselves, and more precisely on how these projects are reflected in the stories they tell in their interviews. Because it is mentioned in the narrations, a type of transmedia narrating is addressed which also has recourse to an autobiographical past. Contents which were absorbed in childhood from various media are invoked from the perspective of the narrators' current life situations and are not only carried over into a new medium with different intentions but are also developed further. Remember the 23-year-old blogger whose interest in fashion was aroused by the magazine Vogue when he was nine years old and which is now one of the topics covered in his blog. He recounted how he engaged with the ambitions which the print medium pursues in relation to its readers, offering that to his readers as a topic of conversation. Another media product, namely the American TV series Gossip Girl, which he had watched many years previously, was the inspiration for his style of writing as a blogger, which he characterized as a "mixture of comedy and drama." As mentioned at several points, a 21 -year-old adopted Gaia, the name of a figure in a novel which she encountered as a child, as her nickname, which reminds her permanently of where she would like to see herself develop.

The transmedia acts directed to the past not only lead to the adoption of media contents; these are also changed under the influence of the new medium and current life questions. ${ }^{5}$ The transfer takes place, if the narratives are anything to go by, as an interaction with the transferred contents, which can also lead to the narrator questioning these contents. The 23-year-old quoted earlier, who declared himself to be a fan of Walt Disney films, described how in his blog he had begun to question the influence of the Walt Disney versions of Sleeping Beauty and Snow White which he watched as a child; he was particularly interested in the understanding of love which these films conveyed ("Whether it really is something that Walt Disney impressed on us in our childhood").

Alongside transmedia narrating rooted in the past, the network actors and bloggers also depict a kind of transmediality stimulated by the current reception of media. Current films and video games are presented, evaluated, and discussed with Others in the narrators' blogs. A 22 -year-old is

\footnotetext{
${ }^{5}$ According to Jenkins, every shift from one medium to another represents an interpretation which adapts and extends the original (2011, para. 12).
} 
proud to talk about the "blog parade" about TV series which she launched. Readers are challenged to report on the setting in which they watch the series by answering the question "How, when, and where do you prefer to watch series?" Comic characters are described as being models for digital self-staging. With the help of make-up and body styling, explained the 24-year-old migrant, she turned herself into the manga character Asuka and that was the image she presented of herself on her homepage. Various network actors and bloggers describe how they take photos of everyday scenarios in their lives and then post them online. One of them includes a literary medium in the form of her own poems in between the photos in her digital galleries. Print media are read online by those who live far away from their home country in order to find topics of conversation when communicating with their families at home, either online or by phone.

For the narrators, it appears to be self-evident that they not only transport their media memories into the here and now but also enliven them in the context of digital media in a novel fashion, incorporating elements of these experiences into new media acts, questioning them critically, or taking them as inspiration for new narrations. The nickname Gaia adopted by one network actor relates a new Gaia story. The style of writing inspired by Gossip Girl is used to tell stories which build on the TV series, yet the stories are different. The way in which the narrators deal with current media experiences is not much different, if their stories are anything to go by. They, too, appear to be perceived as an offer which is not simply consumed but which is also turned this way and that discursively in various media locations, processed in a specific way under the influence of the particular community and the specifics of the medium, provided with new facets of meaning, and used as the raw material for new narrative constructs. In the "blog parade" initiated by one of the bloggers, when "How, when, and where do you prefer to watch TV series" is answered in words, and maybe also in images, many new stories can appear in principle-in line with the options offered by the format of a blog-which can possibly be retold in other media and changed yet again.

The narrations reveal that the narrative threads are laid in a criss-cross fashion, that static images are turned into moving ones in the form of videos, that words become images, images bodies, and bodies images. Claudia Söller-Eckert points out how the transformation of one mode of display into another is possible due to the convergence of media (2013, p. 342 ) as the use of different media is based on similar competences, be 
they communicative, artistic, or literary. The transmedia continuation of stories described by the narrators creates a "flexible cosmos of stories which, although they always have an artistic centre, always have open margins in terms of the dimension of their ongoing development," in Martin Gessmann's words (2013, p. 260). Accessories, things, properties, and designations turn into free-moving utensils in the continuation. Media figures can be equipped with new artefacts which are owed to current life trajectories, as in the case of the imaginary comic figure Asuka, where the blogger places paintbrush, pen, and camera in her hands so as to express the blogger's perspectives of the future.

The narrators generate themselves in their relation to the media not as spectators or mere users; rather they act as designers who co-produce the media contents and, therefore, the media themselves as well (Jenkins, 2011). To go one step further: They contribute not only to the development of individual media but also to the blending of media (Krotz, 2010, p. 108). They appear as subjects, driving forward the mediatization of society by introducing media formats and contents into different spheres of life but above all in the way in which they relate these formats and contents to each other as transmedia narrators.

\section{REFERENCES}

Assmann, A. (2012). Introduction to cultural studies: Topics, concepts, issues (D. H. Wilson, Trans.). Berlin: Erich Schmidt.

Augustin, E. (2015). BlogLife: Zur Bewätigung von Lebensereignissen in Weblogs [BlogLife: Coping strategies for life events in weblogs]. Bielefeld: transcript.

Benjamin, J. (1988). The bonds of love: Psychoanalysis, feminism, and the problem of domination. New York, NY: Pantheon Books.

Böhme, H. (2004). Netzwerke: Zur Theorie und Geschichte einer Konstruktion [Networks: The theory and history of a construction]. In J. Barkhoff, H. Böhme, \& J. Riou (Eds.), Netzwerke: Eine Kulturtechnik der Moderne (pp. 17-36). Köln: Böhlau.

Bolz, N. (2001). Weltkommunikation [World communication]. München: Econ.

Dewey, J. (2009). Democracy and education: An introduction to the philosophy of education [E-book]. Waiheke Island: The Floating Press. (Original work published 1916)

Dirlik, A. (2010). Globale Moderne: Die Moderne im Zeitalter des globalen Kapitalismus weiterdenken [Global modernism: Thinking ahead about modernism in the age of global capitalism]. In M. Boatcă \& W. Spohne (Eds.), 
Globale, multiple und postkoloniale Moderne (pp. 31-52). München: Rainer Hampp.

Erdheim, M. (1984). Die gesellschaftliche Produktion von Unbewußtheit [The social production of unconsciousness]. Frankfurt am Main: Suhrkamp.

Erdheim, M. (1988). Psychoanalyse und das Unbewusste in der Kultur [Psychoanalysis and the unconscious in culture]. Frankfurt am Main: Suhrkamp.

Gessmann, M. (2013). Transmediales Storytelling und die neue Produktsprache im Film: Oder: Was geschieht, wenn sich auch noch Dinge zu Wort melden? [Transmedia storytelling and the new product language in film: Or what happens when things have their say?]. In B. Kracke \& M. Ries (Eds.), Expanded Narration: Das neue Erzäblen (pp. 251-267). Bielefeld: transcript.

Habermas, J. (1992). The structural transformation of the public sphere: An inquiry into a category of bourgeois society ( $\mathrm{T}$. Burger with the assistance of $\mathrm{F}$. Lawrence, Trans.). Cambridge: Polity. (Original work published 1962)

Habermas, T. (2011). Identität und Lebensgeschichte heute: Die Form autobiographischen Erzählens [Identity and life history today: Autobiographical narrative and its form]. Psyche: Zeitschrift für Psychoanalyse und ibre Anwendungen, 65, 646-668.

Hahn, K., \& Koppetsch, C. (2011). Zur Soziologie des Privaten [The sociology of the private]. In K. Hahn \& C. Koppetsch (Eds.), Soziologie des Privaten (pp. 7-16). VS Verlag: Wiesbaden.

Helsper, W. (1997). Das 'postmoderne Selbst': Ein neuer Subjekt- und JugendMythos? Reflexionen anhand religiöser jugendlicher Orientierungen [The 'postmodern' self: A new myth of the subject and youth? Reflections on young people's religious orientations]. In H. Keupp \& R. Höfer (Eds.), Identitätsarbeit heute (pp. 174-206). Frankfurt am Main: Suhrkamp.

Hustvedt, S. (2008). The sorrows of an American. London: Sceptre.

Illouz, E. (2007). Cold intimacies: The making of emotional capitalism. Cambridge: Polity.

Jenkins, H. (2011). Transmedia 202: Further reflections. Retrieved from http:// henryjenkins.org/blog/2011/08/defining_transmedia_further_re.html

Jurczyk, K., \& Oechsle, M. (Eds.). (2008). Das Private neu denken: Erosionen, Ambivalenzen, Leistungen [Rethinking the private: Erosions, Ambivalences, Accomplishments]. Münster: Westfälisches Dampfboot.

Krämer, S., \& Bredekamp, H. (2013). Culture, technology, cultural techniques: Moving beyond text (M. Wutz, Trans.). Theory, Culture o Society, 30(6), 20-29. (Original work published 2003)

Kraus, W. (2000). Identität als Narration: Die narrative Konstruktion von Identitätsprojekten [Identity as narration: The narrative construction of identity projects]. Retrieved from http://web.fu-berlin.de/postmoderne-psych/berichte3/kraus.htm 
Krotz, F. (2010). Leben in mediatisierten Gesellschaften: Kommunikation als anthropologische Konstante und ihre Ausdifferenzierung heute [Living in mediatized societies: Communication as an anthropological constant and its differentiation today]. In M. Pietraß \& R. Funiok (Eds.), Mensch und Medien: Philosophisch und sozialwissenschaftliche Perspektiven (pp. 91-114). Wiesbaden: VS Verlag.

Lacan, J. (1996). The function and field of speech and language in psychoanalysis (B. Fink in collaboration with H. Fink \& R. Grigg, Trans.). In J. Lacan (Ed.), Écrits (pp. 197-268). New York, NY: W. W. Norton. (Original work published 1953)

Langer, S. K. (1957). Philosophy in a new key: A study in the symbolism of reason, rite, and art (3rd ed.). Cambridge, MA: Harvard University Press.

Lévi-Strauss, C. (1966). The savage mind (translation unattributed). London: Weidenfeld and Nicolson. (Original work published 1962)

Lorenzer, A. (1981). Das Konzil der Buchbalter [The council of the bookkeepers]. Frankfurt am Main: Europäische Verlagsanstalt.

Lovink, G. (2011). Networks without a cause: A critique of social media. Cambridge: Polity.

Maresch, R., \& Werber, N. (2002). Permanenzen des Raums [Permanences of space]. In R. Maresch \& N. Werber (Eds.), Raum, Wissen, Macht (pp. 7-32). Frankfurt am Main: Suhrkamp.

Mead, G. H. (with Morris, C. W., Ed.). (1934). Mind, self and society: From the standpoint of a social behaviorist. Chicago, IL: The University of Chicago Press.

Meuter, N. (1995). Narrative Identität: Das Problem der personalen Identität im Anschluss an Ernst Tugendhat, Niklas Lubmann und Paul Ricaur [Narrative identity: The problem of personal identity following Ernst Tugendhat, Niklas Luhmann, and Paul Ricœur]. Stuttgart: Verlag für Wissenschaft und Forschung der J.B. Metzlerschen Verlagsbuchhandlung and Carl Ernst Poeschel Verlag.

Meyer-Drawe, K. (1990). Illusionen von Autonomie [Illusions of autonomy]. München: P. Kirchheim.

Mideast youth. (n.d.). Retrieved from https://mideastyouth.com/

Mitchell, W. J. T. [William]. (2003). Me++: The cyborg self and the networked city. Cambridge, MA: The MIT Press.

Mitchell, W. J. T. [William]. (2005). Placing words: Symbols, space, and the city. Cambridge, MA: The MIT Press.

Mitchell, W. J. T. (1994). Picture theory: Essays on verbal and visual representation. Chicago, IL: The University of Chicago Press.

Mitchell, W. J. T. (2005). What do pictures want? The lives and loves of images. Chicago, IL: The University of Chicago Press.

Müller-Funk, W. (2002). die kultur und ibre narrative: eine einführung [Culture and its narrative: An introduction]. Wien: Springer. 
Nünning, V. (2013). Erzählen und Identität: Die Bedeutung des Erzählens im Schnittfeld zwischen kulturwissenschaftlicher Narratologie und Psychologie [Narrating and identity: The significance of narrating at the intersection of narratology in cultural studies and psychology]. In A. Strohmaier (Ed.), KulturWissen-Narration: Perspektiven transdisziplinärer Erzäblforschung für die Kulturwissenschaften (pp. 145-169). Bielefeld: transcript.

Reichert, R. (2013). Biografiearbeit und Selbstnarration in den Sozialen Medien des Web 2.0 [Biographical work and self-narration in the social media of Web 2.0]. In A. Strohmaier (Ed.), Kultur-Wissen-Narration: Perspektiven transdisziplinärer Erzäblforschung für die Kulturwissenschaften (pp. 511-535). Bielefeld: transcript.

Ries, M. (2013). Erzählen im Netz [Narrating in the net]. In B. Kracke \& M. Ries (Eds.), Expanded Narration: Das newe Erzäblen (pp. 29-44). Bielefeld: transcript.

Roth-Ebner, C. (2015). Der effiziente Mensch: Zur Dynamik von Raum und Zeit in mediatisierten Arbeitswelten [The efficient person: On the dynamics of space and time in mediatized work environments]. Bielefeld: transcript.

Rushdie, S. (2002). Step across this line. In S. Rushdie (Ed.), Step across this line: Collected non-fiction 1992-2002 (pp. 407-442). London: Jonathan Cape.

Schachtner, C., \& Duller, N. (2014). Praktiken des Managements von Privatheit und Öffentlichkeit im Cyberspace: Performative Akte im Kontext des Zeigens und Nicht-Zeigens [Practices for managing the private and the public in cyberspace: Performative acts in the context of showing and not-showing]. Österreichische Zeitschriftfür Soziologie, 13: Subjektivierung 2.0; Machtverbältnisse digitaler Öffentlichkeiten, 61-81.

Sennett, R. (1998). The corrosion of character: The personal consequences of work in the new capitalism. New York, NY: W. W. Norton.

Söller-Eckert, C. (2013). Transmedia Storytelling und Partizipation Experience [Transmedia storytelling and participation experience]. In B. Kracke \& M. Ries (Eds.), Expanded Narration: Das neue Erzäblen (pp. 341-359). Bielfeld: transcript.

Straub, J. (2013). Kann ich mich selbst erzählen—und dabei erkennen? Prinzipien und Perspektiven einer Psychologie des Homo narrator [Can I narrate-and recognize-myself? Principles and perspectives of a psychology of homo narrator]. In A. Strohmaier (Ed.), Kultur-Wissen-Narration: Perspektiven transdisziplinärer Erzählforschung für die Kulturwissenschaften (pp. 75-144). Bielefeld: transcript.

SWR Kindernetz. (2020). Retrieved from www.kindernetz.de 
Open Access This chapter is licensed under the terms of the Creative Commons Attribution 4.0 International License (http://creativecommons.org/licenses/ by $/ 4.0 /$ ), which permits use, sharing, adaptation, distribution and reproduction in any medium or format, as long as you give appropriate credit to the original author(s) and the source, provide a link to the Creative Commons licence and indicate if changes were made.

The images or other third party material in this chapter are included in the chapter's Creative Commons licence, unless indicated otherwise in a credit line to the material. If material is not included in the chapter's Creative Commons licence and your intended use is not permitted by statutory regulation or exceeds the permitted use, you will need to obtain permission directly from the copyright holder. 